\title{
Entrevista
}

\section{Entrevista com a professora Fabiane Popinigis (UFRRJ)}

\author{
Interview with Professor Fabiane Popinigis (UFRRJ)
}

\author{
Renata Figueiredo Moraes* \\ Universidade do Estado do Rio de Janeiro, Brasil \\ Paulo Cruz Terra** \\ Universidade Federal Fluminense, Brasil
}

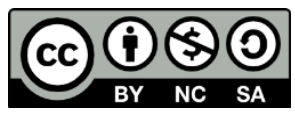

A entrevistada nesta edição, Fabiane Popinigis, tornou-se, em 2018, a coordenadora do Grupo de Trabalho - Mundos do Trabalho (GT-MT). Este foi criado em 2000, com a oficialização junto à diretoria da Associação Nacional de História (ANPUH), constituindo-se em um espaço, que não existia até então no Brasil, de reunião e troca entre pesquisadores, de diferentes regiões e universidades de país, interessados na história do trabalho. O tema central do presente dossiê, as relações entre trabalho livre e escravo, esteve desde o início presente na definição do escopo e da agenda de pesquisa do GT.

A escolha de Popinigs como entrevistada deste número, no entanto, vai muito além do fato de ela ser coordenadora do GT-MT. Com formação pela Universidade Estadual de Campinas

\footnotetext{
* Professora Adjunta de História do Brasil, do Instituto de Filosofia e Ciências Humanas, da Universidade do Estado do Rio de Janeiro. Doutora em História Social da Cultura pela Pontifícia Universidade Católica do Rio de Janeiro; Mestre e graduada em História pela Universidade Federal Fluminense. (renatafm2003@yahoo.com.br)

CV Lattes: http://lattes.cnpq.br/7422043520205798

** Professor Adjunto de História do Brasil, do Instituto de História, da Universidade Federal Fluminense. Doutor e Mestre em História pela Universidade Federal Fluminense; graduado em História pela Universidade Estadual de Campinas. (pauloterra@gmail.com)

CV Lattes: http://lattes.cnpq.br/3005228142189797
} 
(UNICAMP) - desde a graduação até o doutorado -, sua tese, premiada no concurso Várias Histórias do Centro de Pesquisa em História Social da Cultura (CECULT), é um estudo de grande impacto e relevância sobre os trabalhadores no século XIX, o que quebrava uma barreira na historiografia do trabalho, já que as investigações geralmente se resumiam ao período pós-1888 por considerarem incompatível o desenvolvimento da classe operária com a existência da escravidão. Ao investigar as formas de mobilização e organização dos caixeiros no Rio de Janeiro ao longo do Império e da Primeira República, a autora foi pioneira em apontar, por exemplo, a relação dos trabalhadores com os poderes municipais. Professora do Departamento de História e do Programa de Pós-graduação em História da Universidade Federal Rural do Rio de Janeiro (UFRRJ), Popinigis tem realizado recentemente importantes reflexões que envolvem classe, raça e gênero.

\section{1) O Grupo de Trabalho "Mundos do Trabalho" (GT-MT), que você passou a coordenar em 2018, foi criado em 2001 no âmbito da Associação Nacional de História (ANPUH). Como você avalia a importância do GT-MT para a consolidação e desenvolvimento da historiografia do trabalho no país?}

O GT mundos do Trabalho foi formado por pesquisadores interessados em unir esforços para criar um espaço institucional que os agregasse possibilitando um âmbito de debates e de divulgação para as pesquisas no campo.

Desde seu início o grupo contou com pesquisadoras e pesquisadores que tinham perspectivas muito diversas sobre o que fossem os mundos do trabalho. Em sua reunião de fundação, numa Anpuh Nacional que aconteceu na USP em 2001, discutiu-se tanto a formulação plural - mundos, e não mundo do trabalho - quanto quem eram os sujeitos e relações que se incluíam nesse campo. Assim, foi reivindicado que não apenas trabalhadores industriais e suas organizações fossem incluídos, mas trabalhadores rurais, trabalhadores escravizados e, no meu caso, por exemplo, o objeto de interesse eram os empregados no comércio, entre outros.

Esse processo se deu juntamente com a organização da ANPUH, cada vez mais em torno dos simpósios temáticos propostos pelos próprios grupos de trabalho (os GT's). Isso permitiu que professores pesquisadores sêniors se reunissem para apresentar, debater e divulgar suas pesquisas, atraindo também jovens pesquisadores que passaram a renovar esse campo historiográfico, bem como interessados que transitam entre diversos campos consolidados e novos grupos que foram sendo criados. Hoje o grupo tem uma página na internet, nas redes sociais, uma Revista, organiza um evento internacional bianual, além de três simpósios na ANPUH Nacional. Está na iminência da criação de uma associação própria também. 


\section{2) Em termos da história do trabalho produzida no Brasil, que mudanças são possíveis verificar desde a criação do GT-MT?}

Avaliando a trajetória do grupo e seu histórico, pode-se perceber alguns movimentos. Um deles é uma convivência, as disputas e negociações para a escolha de temas para os simpósios e para mesas redondas ou palestras dentro do grupo, que foi abrindo espaço para objetos de pesquisa e abordagens que não estivessem tão no centro do debate e fossem tomando corpo, num processo constante.

Desde o final da década de 1880 vinha havendo uma ampliação do que seria objeto de interesse na história social do trabalho - homens e mulheres exercendo seus ofícios e atividades para a própria subsistência, suas relações e processos de trabalho e suas experiências de vida. As perspectivas teórico-metodológicas também foram sofisticadas para incorporar elementos e dimensões do simbólico na vida cotidiana e política dessas trabalhadoras e trabalhadores, as interações entre instâncias da vida comunitária, nas sociabilidades e a criação de identidades em torno dos mais diversos aspectos de suas experiências.

Houve e tem havido mudanças conceituais que nos levam a, cada vez mais, perceber esses objetos em sua complexidade, buscando não apenas incluir - sabemos que vários grupos de mulheres sempre trabalharam e que os escravizados também faziam greves, por exemplo, que organizavam movimentos de resistências, que fundavam associações (irmandades, sociedades...). Assim, é preciso fazer perguntas de investigação sobre as lógicas próprias dos agentes, sua experiência, suas relações e seus significados em contextos específicos - bem como as diferentes formas de articulação do poder nesses mesmos contextos - para compreender os processos históricos.

Institucionalmente falando, além do aumento do número de participantes - é um dos maiores grupos da ANPUH Nacional hoje - percebe-se a formação de diversos núcleos regionais que estão hoje bem espalhados e ativos em todas as regiões. Dois movimentos foram fundamentais nessa ampliação: a criação dos Encontros Internacionais do GT, nos anos pares, alternando com os SNH's, e a criação da Revista Mundos do Trabalho. Isso ampliou expressivamente os campos de diálogo e a circulação internacional dos pesquisadores e pesquisadoras e sua produção, tanto na América Latina quanto entre grupos e âmbitos de historiadores do chamado sul global - especialmente indianos, mas também africanos - e na Europa e nos EUA.

\section{3) Quais temas e perspectivas você acredita que ainda precisam ser mais explorados pelos estudos dedicados aos mundos do trabalho?}


É fundamental investir nas pesquisas sobre o papel do racismo no mercado de trabalho no século $X X$, nas disputas trabalhistas, nas políticas de Estado, na formação dos sindicatos e partidos políticos, nas pautas das demandas dos movimentos sociais, na organização dos movimentos sociais, nas condições de vida e trabalho de homens e mulheres negras. É preciso também aprofundar estudos e estimular pesquisas que se preocupem em pensar sobre a cor na formação do mercado de trabalho, as lógicas próprias dos trabalhadores escravizados e dos negros libertos nas relações sociais e na organização de movimentos, como tem sido feito para o século XIX e para a virada para o XX.

A perspectiva de gênero nos estudos de história social do trabalho no Brasil foi, com honrosas exceções, deixada de lado. Diferente de outras historiografias, que foram inclusive extremamente inspiradoras para os historiadores sociais do trabalho no Brasil, nas quais há uma vasta e importante produção sobre condições de moradia e família nas comunidades de trabalhadores no período de industrialização, participação das mulheres nas greves, sindicatos e movimentos sociais, para citar temas clássicos da história do trabalho - mas não só. Para dar apenas dois exemplos - a história social inglesa e a argentina podem ser inspiradores para pensarmos temas e abordagens que praticamente não foram tocados pela história do trabalho brasileira. Além desses temas mais tradicionais, há também o caso das ocupações, atividades e profissões que foram pouco ou nada estudadas por não serem consideradas interessantes ou parte desses mundos do trabalho (não-industriais, não-remuneradas/assalariadas, não estáveis), e em perspectiva de gênero.

Deveríamos voltar a um problema clássico da sociologia do trabalho com olhos de historiadores sociais, que é a divisão sexual do trabalho. E não são estudos específicos, isolados. Afinal, em qualquer pesquisa sobre temas consolidados de história social do trabalho podemos nos perguntar de que forma se articulam marcadores sociais como gênero, raça e etnicidade e idade nos espaços de trabalho e sobre as relações de poder que se geram em toda a vida social, particularmente nas relações laborais, criando ou reproduzindo e consolidando desigualdades. Porque aí se vão gerando processos de produção de significados para o valor desses trabalhos, muito ligados às representações sobre feminilidade e masculinidade das ocupações e das representações sobre elas (e não necessariamente por serem exercidas por mulheres e homens) e então entram remuneração, salário, organização social, força reivindicativa, status, dignidade.

Além disso, é urgente superar a construção dicotômica do mundo da domesticidade em oposição ao mundo trabalho, e do público/privado para avançar na questão do trabalho das mulheres e das representações sobre o que eram trabalhos "masculinos" e trabalhos "femininos", quem os realizava e por que.

Finalmente, na conjuntura atual, há uma evidente e urgente demanda para entender o papel da religião na política e a expansão e crescimento das igrejas evangélicas e seus representantes no parlamento e em espaços estratégicos de organização social. Sobretudo, é 
necessário um esforço de compreensão das dinâmicas de influência da religião na ação dos trabalhadores.

\section{4) A história global tem se tornado uma forte tendência historiográfica mundial, inclusive no campo dos estudos sobre o trabalho. Como você avalia as possibilidades da história global do trabalho?}

A história global do trabalho propõe, entre outras coisas, buscar uma visão mais sistêmica dos processos considerados "globais", por implicarem agentes, movimentos, relações, capitais, produtos e circulação envolvendo várias regiões do globo, processos que não poderiam ser compreendidos se os campos de investigação fossem limitados pela lógica do tempo e espaço dos estados-nação. É importante lembrar que isso não é totalmente novo, pois vem dentro de um contexto de várias outras formas de pensar as conexões espaciais e temporais dos processos históricos, como a história conectada e transnacional e atentar para que o estudo de outras regiões não seja apenas um complemento das analises sobre a Europa ou os EUA e seus circuitos, sobretudo pela desigualdade do acesso à recursos e fontes.

Na minha opinião é fundamental não perder de vista ou desconsiderar os ganhos trazidos à história social pelo largo movimento anterior da historiografia, conduzido pela micro-história contestava as grandes analises estruturalistas, buscando valorizar respostas locais e específicas para perguntas gerais, com exame denso e minucioso desses contextos, enxergando indivíduos, experiências e relações que de outra forma não se poderia perceber.

No caso da história global do trabalho, acho que uma das mais importantes contribuições, que inclusive contempla o tema do dossiê deste número sobre trabalho escravo/trabalho livre, é justamente a ampliação do conceito de classe trabalhadora, o que é ótimo. Mas isso deve ser ainda mais expandido para incluir também o âmbito da domesticidade e o trabalho reprodutivo. Como tem mostrado a crítica feminista há décadas, reduzir a importância do estudo dos trabalhadores ao trabalho assalariado exclui também o trabalho das mulheres, não só antes como depois da abolição.

5) No que diz respeito especificamente às pesquisas que tratam da relação entre trabalho livre e escravo, tema do presente dossiê, quais foram os avanços da historiografia produzida no Brasil?

É interessante porque essa é a parte em que a história social do trabalho mais dialogou com a historiografia sobre a escravidão, e ambas receberam muita influência do historiador inglês E.P. Thompson. Entre esses pontos de contato, estavam as metodologias de análise, que 
primavam por uma leitura eminentemente histórica, contextual e relacional do processo, rejeitando modelos prontos, e assim também buscando a compreensão das lógicas próprias dos sujeitos, reconhecendo que eram capazes de formular estratégias e de agir pautados pela sua experiência.

Assim, se para a história social do trabalho a obra fundamental de Thompson foi $A$ Formação da Classe Trabalhadora Inglesa, para os historiadores da escravidão, foram os artigos depois reunidos na coletânea Costumes em Comum. Mas é no cruzamento das questões de comunidade, identidade, poder (sua articulação e contestação) que estão os elementos mais interessantes desse ponto. Inclusive aí o Senhores e Caçadores também é fundamental para construir a ideia de que a lei e o direito são elementos importantes para os historiadores e historiadoras investigarem e conhecerem as relações de poder e as lutas por direitos em diferentes períodos históricos.

Praticamente desde que se iniciou a prática de propor simpósios aos eventos bianuais da ANPUH Nacional, o GT Mundos do Trabalho buscou contemplar a temática do trabalho escravotrabalho livre (ou nas suas margens) com um simpósio exclusivamente dedicado a ela. Isso veio criando um espaço de debates que tem sido um dos mais profícuos inclusive. As pesquisas aí apresentadas são muito diversas, mas em grande parte tem uma de suas origens naquelas que mostraram que os trabalhadores escravizados sabiam muito bem o valor do seu trabalho, pois costumavam exercer atividades e ofícios como formas de acumular pecúlio para a compra da alforria - os escravos ao ganho; libertas, as mulheres africanas e descendentes que trabalhavam com o comercio de gêneros, por exemplo, tinham acesso ao crédito, eram credoras de homens politicamente importantes e controlavam ou faziam parte de redes de trabalho urbano, bem como de irmandades e outras formas de associação. Outra importante contribuição, que ainda precisa ser muito explorada, foram as pesquisas que mostraram que homens e mulheres escravizados trabalhavam lado a lado de trabalhadores "livres" e outros tipos de contratados, como colonos e em parceria em fábricas e manufaturas do século XIX.

A importância desses trabalhos foi mostrar, entre outras coisas que, - no primeiro caso as mulheres negras, que sempre trabalharam, eram parte fundamental do funcionamento do mercado de trabalho urbano e, no segundo, matizar a ideia dicotômica que colocava trabalhadores escravizados de um lado, trabalhando na lavoura, e uma massa de imigrantes brancos que chegava ao pós-abolição para o trabalho assalariado nas fábricas no processo de industrialização. Várias pesquisas mostraram e tem mostrado um quadro bem mais complexo do que levava a crer uma ideia de "transição do trabalho escravo para o trabalho livre" impulsionada pelo avanço do capitalismo industrial. Graças aos estudos recentes dentro e fora do Brasil sabemos hoje que o século XIX não foi de transição para o trabalho assalariado, mas sim de diversificação das formas de exploração do trabalho desses homens e mulheres e seus status 
jurídicos e que no imediato pós abolição a tendência majoritária provavelmente não foi o assalariamento.

Outro desdobramento importante dessas linhas de pesquisa são os trabalhos que transitam entre história e direito, partindo de questões candentes na atualidade sobre o trabalho análogo ao escravo, as migrações e suas atualizações sobre dignidade humana. A existência, no mundo todo de uma grande parte das pessoas vivendo nessas condições de escravidão, me parece, coloca em xeque narrativas lineares de progresso do assalariamento como condição predominante, entre outras coisas.

\section{6) No contexto atual do país pós-reforma trabalhista e de possibilidade concreta de reforma da previdência, quais os desafios para os historiadores do mundo do trabalho? Você acredita que tem crescido o interesse por essa temática?}

Bem, isso precisa ser respondido por dois lados.

Vou começar pelo desafio institucional que esse governo nos impõe. Além da redução dos financiamentos e do ataque à ciência que já estamos vivendo, há os cortes e a diminuição de bolsas que afetam diretamente os programas de pós-graduação e as iniciações científicas. As universidades e os programas de pós-graduação recém-criados estavam em expansão e estão sendo duramente afetados. Sabemos da imensa importância da expansão da universidade pública e da inclusão de grupos que antes não se viam contemplados.

A elitização dos espaços acadêmicos, antes, criou um sentimento de não pertencimento, de afastamento dessas pessoas, mulheres e homens negros, moradores das periferias, indígenas, quilombolas, que consideravam que aquele espaço não era para eles. Embora ainda houvesse um longo caminho a percorrer, a faísca de inclusão pelo ensino que vivenciamos já trouxe resultados transformadores, inclusive nos interesses de pesquisa. Ao que tudo indica o objetivo deste governo é justamente reverter esses avanços, então vamos ter dificuldades em dobro, e nosso papel vai ser de resistência a esses retrocessos e também de criatividade para conseguir manter os vínculos e as redes internacionais que criamos e começamos a expandir.

Em relação às temáticas propostas pela história do trabalho eu acho que agora é um momento crítico e revelador da importância de estudos que levem em conta as dimensões de classe social de seus objetos, de pensar temas clássicos de história do trabalho com novas perguntas e abordagens.

Nesse sentido da conjuntura nacional e internacional a questão mais evidente para quem começa a estudar é pensar como os direitos de todo tipo são sempre conquistados depois de muita luta e mobilização; de como se dão as disputas em relação ao papel do estado em todas as suas esferas na mediação dos conflitos capital-trabalho, legislação trabalhista e os limites da democracia; nos direitos humanos e as grandes migrações; nas relações entre as instâncias legais 
e jurídicas e as ruas; nas dimensões simbólicas e políticas das tensões do cotidiano das pessoas comuns.

Ou seja, num momento de crise do emprego, do trabalho, dos direitos, da indústria, da política, pode ser também o momento de fazer boas perguntas e de investir na pesquisa e na história pública, de divulgação da produção científica, de fortalecer o diálogo com os movimentos sociais. Temos visto uma onda de revisionismo histórico sobre ditaduras e direitos humanos e a produção de fake News ocupando boa parte das novas mídias bem como ataques à própria ideia de conhecimento. É urgente que a gente se que mobilize para dialogar com um público mais amplo sobre como fazer pesquisa com essas novas ferramentas e também para fazer circular nossa produção em diálogo com a comunidade não acadêmica nesses outros formatos. 